LIVER

\title{
Randomised controlled trial of long term portographic follow up versus variceal band ligation following transjugular intrahepatic portosystemic stent shunt for preventing oesophageal variceal rebleeding
}

\author{
D Tripathi, H F Lui, A Helmy, K Dabos, E Forrest, A J Stanley, R Jalan, D N Redhead, P C Hayes
}

Gut 2004;53:431-437. doi: 10.1136/gut.2003.013532

See end of article for authors' affiliations

\section{Correspondence to:} Dr D Tripathi, Liver Unit, Royal Infirmary, 51 Little France Crescent,

Edinburgh EH16 4SU, UK; d.tripathi@ed.ac.uk

Accepted for publication 2 September 2003

\begin{abstract}
Background/aims: Transjugular intrahepatic portosystemic stent shunt (TIPSS) is effective in the prevention of variceal rebleeding but requires invasive portographic follow up. This randomised controlled trial aims to test the hypothesis that combining variceal band ligation (VBL) with TIPSS can obviate the need for long term TIPSS surveillance without compromising clinical efficacy, and can reduce the incidence of hepatic encephalopathy.

Patients/methods: Patients who required TIPSS for the prevention of oesophageal variceal rebleeding were randomised to either TIPSS alone $(n=39$, group 1$)$ or TIPSS plus VBL $(n=40$, group 2$)$. In group 1 , patients underwent long term TIPSS angiographic surveillance. In group 2, patients entered a banding programme with TIPSS surveillance only continued for up to one year.

Results: There was a tendency to higher variceal rebleeding in group 2 although this did not reach statistical significance $18 \% \vee 15 \%$; relative hazard 0.58 ; $95 \%$ confidence interval (CI) $0.15-2.33$; $\mathrm{p}=0.440$ ). Mortality (47\% v 40\%; relative hazard $1.31 ; 95 \% \mathrm{Cl} 0.66-2.61 ; \mathrm{p}=0.434$ ) was similar in the two groups. Hepatic encephalopathy was significantly less in group 2 (20\% v39\%; relative hazard 2.63; $95 \% \mathrm{Cl} 1.11-6.25 ; p=0.023)$. Hepatic encephalopathy was not statistically different after correcting for sex and portal pressure gradient $(p=0.136)$.

Conclusions: TIPSS plus VBL without long term surveillance is effective in preventing oesophageal variceal rebleeding, and has the potential for low rates of encephalopathy. Therefore, VBL with short term TIPSS surveillance is a suitable alternative to long term TIPSS surveillance in the prevention of oesophageal variceal rebleeding.
\end{abstract}

$\mathrm{V}$ ariceal bleeding is a serious complication of portal hypertension with inhospital mortality of 30-50\% depending on the severity of liver disease. ${ }^{1}$ Mortality following variceal rebleeding is as high as $78 \%$ in patients with advanced hepatic decompensation. ${ }^{2}$ Transjugular intrahepatic portosystemic stent shunt (TIPSS) is superior to variceal band ligation (VBL) in the prevention of variceal rebleeding although patients are more likely to develop hepatic encephalopathy and patient survival is unaffected. ${ }^{3-11}$ Long term patency of TIPSS is also a clinical problem. Studies indicate that without regular TIPSS surveillance and intervention, approximately $50 \%$ of stents will occlude after one year. ${ }^{12-17}$ Regular invasive portographic surveillance, which is essential for maintaining shunt patency, is not available in all centres, and places an additional burden on resources. Moreover, non-invasive methods of assessing TIPSS patency such as Doppler ultrasound are not as sensitive as regular portography, ${ }^{18}$ and lead to a higher rebleeding rate. ${ }^{3}$ In any case, Doppler ultrasound does not allow for interventions, such as balloon angioplasty and re-stenting, or for measurement of portal pressures.

VBL has replaced injection sclerotherapy in most centres as the favoured endoscopic treatment for the prevention of variceal rebleeding. VBL is associated with a high rate of rebleeding, particularly in the month following the index variceal bleed. ${ }^{7}$ However, once the varices have been eradicated, VBL may be as effective as a patent TIPSS in preventing variceal rebleeding. Thus following variceal eradication in a patient with a TIPSS, it may not be necessary to continue TIPSS surveillance to maintain TIPSS patency. It is not known whether terminating angiographic TIPSS surveillance following successful VBL will compromise the variceal rebleeding rate.

We hypothesised that combining VBL and TIPSS with short term portographic surveillance would be as effective as TIPSS alone with long term surveillance in the prevention of oesophageal variceal rebleeding. Patients in the former group could benefit from the reduced need for angiographic surveillance and incidence of hepatic encephalopathy as TIPSS is allowed to occlude following variceal eradication. There may also be cost advantages in using VBL instead of long term TIPSS surveillance.

Therefore, the aim of this randomised controlled trial was to compare the efficacy of TIPSS plus VBL without long term surveillance, with TIPSS and long term surveillance in the secondary prevention of oesophageal variceal rebleeding. Other potential differences such as mortality, encephalopathy, and costs were also explored.

\section{METHODS}

The trial was undertaken with the approval of the local research ethics committee, written informed consent of each subject, and in accordance with the Declaration of Helsinki (1989) of the World Medical Association.

Abbreviations: PPG, portal pressure gradient; TIPSS, transjugula intrahepatic portosystemic stent shunt; VBL, variceal band ligation; OLT, orthotopic liver transplantation 


\section{Patients selection}

Between December 1995 and August 2000, a total of 303 patients were referred for TIPSS insertion from centres throughout Scotland. All TIPSS procedures were performed at the Royal Infirmary, Edinburgh. All patients presenting with bleeding oesophageal varices were considered for inclusion into the trial. Exclusion criteria are as follows: (1) technical failure of TIPSS insertion; (2) age $<18$ or $>85$ years; (3) bleeding gastric or ectopic varices; (4) portal vein thrombosis; (5) Budd-Chiari syndrome; (6) ascites as a primary indication for TIPSS; (7) advanced cardiopulmonary disease; (8) malignancy with prognosis that will affect study outcome; (9) inability to give informed consent; (10) previous variceal haemorrhage; and (11) pregnancy or women of childbearing potential not taking contraception. Patients were recruited after haemodynamic stabilisation.

\section{Randomisation and treatments}

Prior to TIPSS, all patients were resuscitated with fluids and blood or blood products, and underwent endoscopy with VBL or sclerotherapy using $5 \%$ ethanolamine oleate if there was active bleeding. In some patients, pharmacological intervention with octreotide or terlipressin was undertaken. Randomisation was performed following TIPSS insertion and only after initial control of bleeding and haemodynamic stabilisation. Patients were allocated to either group 1 or group 2 using the sealed envelope method. ${ }^{19}$

\section{Group 1: TIPSS alone}

At the time of the index endoscopy, active variceal bleeding was noted in 23 patients. VBL was performed in 13 patients, VBL and sclerotherapy in one patient, and sclerotherapy in six patients. In three patients it was not possible to control bleeding with endoscopic therapies requiring the use of balloon tamponade. In 16 patients there were stigmata of recent bleeding but no active bleeding, with three patients having VBL and one both VBL and sclerotherapy. The remainder proceeded straight to TIPSS. All TIPSS procedures in recruited patients were performed or closely supervised by a skilled interventional radiologist using a standard technique described elsewhere. ${ }^{20}$ All patients were administered broad spectrum antibiotics pre- and for 48 hours postprocedure. Ten to $14 \mathrm{~mm}$ diameter expandable metal stents (Wallstent, Schneider, Switzerland) were used with the aim of reducing the portal pressure gradient (PPG) to $<12 \mathrm{~mm} \mathrm{Hg}$ or by $\geqslant 20 \%$. This was achieved in $36(92 \%)$ and $37(93 \%)$ patients in groups 1 and 2, respectively. Two or more stents were used, if necessary, to cover the entire length of the tract between the hepatic vein and portal vein.

Following creation, TIPSS function was assessed at one week by colour Doppler ultrasound. Routine portographic follow up with intervention, if required, to maintain shunt patency was undertaken at six monthly intervals thereafter. However, additional TIPSS portography was also performed where there was clinical suspicion of TIPSS insufficiency, such as rebleeding.

\section{Group 2: TIPSS plus VBL}

At the time of the index TIPSS, 28 patients were actively bleeding from varices. Eighteen patients required VBL, two patients VBL and sclerotherapy, and four sclerotherapy. Four patients failed endoscopic therapy requiring balloon tamponade and urgent TIPSS. In 12 patients there were stigmata of recent bleeding but not active bleeding, with six patients having VBL, and the remainder proceeding to TIPSS. The TIPSS procedure was performed as above. Following satisfactory haemodynamic stabilisation of the patient, VBL was undertaken or closely supervised by an experienced endoscopist. One of two banding devices was used (Speedbander,
Boston Scientific, Herts, UK; or 6-Shooter Saeed Multi-Band Ligator, Cook, Ireland), deploying 5 or 6 bands, respectively. Varices just above the gastro-oesophageal junction were banded using a single band at a time. A varix was considered eradicated if the column had disappeared or if they could not be sucked into the banding device. It should be noted that in patients with a patent TIPSS, varices often appear collapsed and therefore require suction for their size to be appreciated and VBL to be performed.

Repeat endoscopy with or without VBL was performed within a week of TIPSS insertion and at two weekly intervals until variceal eradication. Intervals were extended to three and six months thereafter. Shunt function was assessed as previously mentioned. Portographic follow up was continued for up to 12 months following TIPSS insertion in all patients but was discontinued earlier in patients where variceal eradication was achieved.

\section{Follow up}

All subjects were followed up until death, liver transplantation, or lost to follow up. A specialist research nurse coordinated clinical follow up, with full clinical examination and biochemical profile at six weeks post-randomisation and four monthly thereafter.

\section{Outcomes}

Rebleeding

Rebleeding was defined as subsequent haematemesis or melaena with a $20 \mathrm{~g} / \mathrm{l}$ reduction in haemoglobin requiring an unscheduled endoscopy.

\section{Early mortality}

This was defined as death within six weeks of the index variceal bleed.

\section{Hepatic encephalopathy}

This was assessed prior to and during follow up, as already mentioned, and was classified as de novo or deterioration of pre-existing encephalopathy using the criteria of ParsonSmith and colleagues. ${ }^{22}$

\section{Shunt insufficiency}

This was defined as an increase in PPG to $>12 \mathrm{~mm} \mathrm{Hg}$ or an increase in PPG of more than $20 \%$ of the immediate postTIPSS value. ${ }^{14}$

Outcomes were assessed at 6, 12, and 24 months. The primary outcome of the study was variceal rebleeding. Secondary outcomes were mortality, incidence of encephalopathy, and orthotopic liver transplantation (OLT).

\section{Sample size calculation}

Sample size was calculated to show that both treatments were equally effective in preventing rebleeding. ${ }^{21}$ Assuming that both treatments were expected to have a $10 \%$ variceal rebleeding rate, and with a type I error $(\alpha)$ of 0.05 and a type II error $(\beta)$ of $0.2,38$ patients would be required in each arm to demonstrate the equivalence (assumed as $<17 \%$ difference) of the two treatments. Once sufficient numbers were reached in each arm, recruitment stopped and the study was terminated four months after the last patient was recruited.

\section{Calculation of costs of treatment}

Data regarding the time spent by each patient in a general, intensive care, or high dependency ward during the follow up period were retrieved. Costs were based on data from the National Health Service, our Department of Radiology, and our Endoscopy Unit. Costs are expressed as cost per patient and also the cost per month survival. The latter is the overall 


\begin{tabular}{|c|c|c|}
\hline Characteristic & TIPSS $(n=39)$ & TIPSS + VBL $(n=40)$ \\
\hline Age (y) (range) & $53.9(11.2)(32-74)$ & $55.9(11.4)(30-82)$ \\
\hline Male sex (n (\%)) & $30(77 \%)$ & $22(55 \%)^{*}$ \\
\hline Child-Pugh score (at baseline) & $9.2(2.1)$ & $8.7(2.3)$ \\
\hline \multicolumn{3}{|l|}{ Aetiology (n (\%)) } \\
\hline Alcoholic & $28(72 \%)$ & $35(88 \%)$ \\
\hline Abstained from alcohol & $8(29 \%)$ & $10(29 \%)$ \\
\hline Non-alcoholic & $11(25 \%)$ & $5(13 \%)$ \\
\hline \multicolumn{3}{|l|}{ PPG $(\mathrm{mm} \mathrm{Hg})$} \\
\hline Pre-TIPSS & $25.2(6.6)$ & $20.1(6.1)^{* *}$ \\
\hline Post-TIPSS & $7.2(4.0)$ & $6.6(4.4)$ \\
\hline Requirement for mechanical ventilation (n (\%)) & $5(13 \%)$ & $6(15 \%)$ \\
\hline Time from index bleed to randomisation (days) & $8.1(6.8)$ & $6.3(5.5)$ \\
\hline Time from TIPSS insertion to randomisation (days) & $3.3(2.9)$ & $2.9(3.3)$ \\
\hline Blood transfusion at randomisation (units) & $3.5(4.2)$ & $2.7(2.6)$ \\
\hline Hypotensive at randomisation (n (\%)) & $6(15 \%)$ & $4(10 \%)$ \\
\hline \multicolumn{3}{|c|}{$\begin{array}{l}\text { Values are mean (SD) unless stated otherwise. } \\
\text { TIPSS, transjugular intrahepatic portosystemic stent shunt; VBL, variceal band ligation; PPG, portal pressure } \\
\text { gradient. } \\
{ }^{*} p=0.040 ;{ }^{* *} p<0.001 \text {. }\end{array}$} \\
\hline
\end{tabular}

cost per patient divided by the follow up time in months (table 4).

\section{Costs of ward beds}

The cost per day in a general ward is $£ 350$, high dependency ward is $£ 500$, and an intensive care ward is $£ 1200$. These costs include staff and consumables.

\section{Cost of TIPSS procedure and follow up}

The consumable cost of the TIPSS procedure is $£ 1679$. Follow up costs are as follows: routine portography (£205), balloon angioplasty $(£ 371)$, shunt reduction $(£ 753)$, insertion of a caval filter and coils for the purposes of occluding the shunt (£785), shunt extension (£927), and insertion of a parallel shunt $(£ 1462)$.

\section{Cost of VBL}

The cost of the endoscopy session is $£ 250$. Where VBL is also required, the overall cost increases to $£ 350$.

\section{Statistical analysis}

Data were analysed on an intention to treat basis. Baseline characteristics were described in the two groups using summary statistics. The $\chi^{2}$ test was used to compare nonparametric data, and the Student's $t$ test was used to compare parametric data. Kaplan-Meier graphs and log rank tests were applied to survival, rebleeding, encephalopathy, and shunt insufficiency. Cox regression analysis was used to control for sex and PPG pre-TIPSS. Significance was taken at the 5\% level. The SPSS statistics package (version 9; Chicago, Illinois, USA) was used for all statistical analyses.

\section{RESULTS}

\section{Patients recruited}

Seventy nine patients met the inclusion criteria, with 39 were randomised to group 1 and 40 to group 2 (fig 1 ). There were no patients excluded from the trial after randomisation. Mean follow up period was 22.5 (17.2) months (range 0.158.9) and 26.6 (18.1) months (range 0.3-64.1) in groups 1 and 2 , respectively.

\section{Baseline characteristics}

There were more male patients and PPG pre-TIPSS was higher in the TIPSS alone arm. Clinical parameters of the two groups are shown in table 1.

\section{Procedures}

TIPSS insertion was complicated by an intraperitoneal bleed in one patient in group 1. In another patient in group 2, there was a biliary leak leading to a percutaneous fistula and suprahepatic abscess. This patient developed respiratory failure and staphylococcal septicaemia requiring antibiotics, vasoconstrictor therapy, and ventilation. The suprahepatic abscess was drained percutaneously. The patient then made an uneventful recovery. In $73(92 \%)$ patients there was a reduction in PPG following TIPSS insertion to $<12 \mathrm{~mm} \mathrm{Hg}$, and in all patients except one there was a $>20 \%$ reduction in PPG post-TIPSS. Mean diameter of the stents was similar in the two groups.

VBL post-TIPSS insertion was performed successfully in 38 patients in group 2. One patient rebled before VBL could take place and another refused banding. A total of 176 endoscopies were performed during the follow up period. VBL was required in 69 endoscopies, with 47 (68\%) procedures performed in the first three sessions. Successful eradication

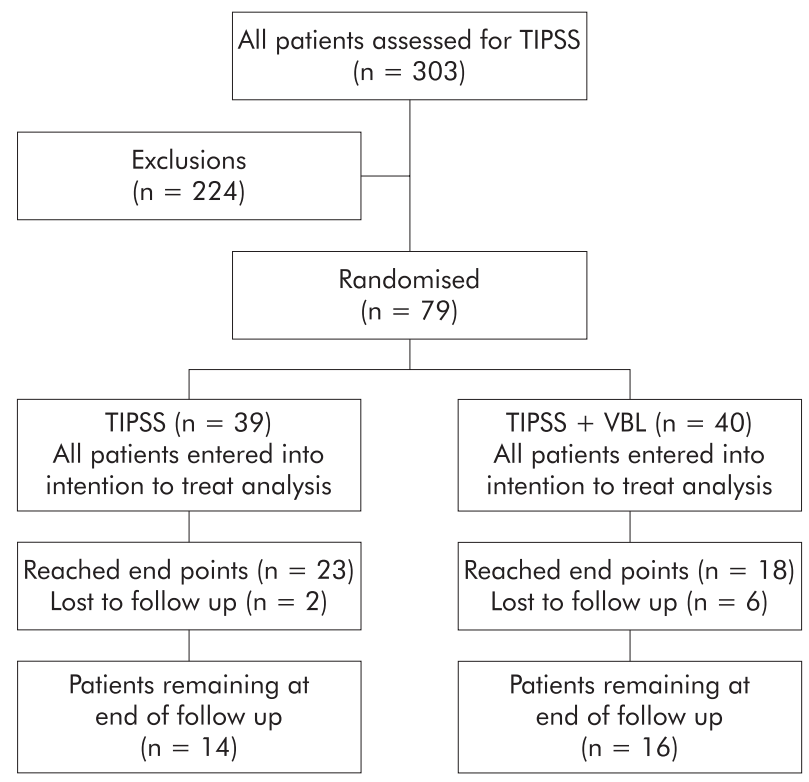

Figure 1 Flow diagram of patient recruitment (see text for exclusion criteria). Patients who reached the end points after randomisation and withdrew from the trial had one of the following events: (1) death; (2) liver transplantation; or (3) variceal rebleeding. 
Table 2 Details of trial outcomes

\begin{tabular}{|c|c|c|c|c|}
\hline & TIPSS & TIPSS+VBL & $\begin{array}{l}\text { TIPSS/TIPSS+VBL relative hazard over entire } \\
\text { follow up }(95 \% \mathrm{CI})^{*}\end{array}$ & p Value* \\
\hline Mortality (n (\%)) & & & $1.31(0.66-2.61) / 1.10(0.53-2.28)$ & $0.434 / 0.803$ \\
\hline 6 month & $5(13 \%)$ & $2(5 \%)$ & & \\
\hline 12 month & $8(21 \%)$ & $6(15 \%)$ & & \\
\hline 24 month & $14(36 \%)$ & $11(28 \%)$ & & \\
\hline Variceal rebleeding (n (\%)) & & & $0.58(0.15-2.33) / 0.39(0.09-1.77)$ & $0.440 / 0.221$ \\
\hline 6 month & 0 & $3(8 \%)$ & & \\
\hline 12 month & $1(3 \%)$ & $5(13 \%)$ & & \\
\hline 24 month & $3(8 \%)$ & $6(15 \%)$ & & \\
\hline Hepatic encephalopathy (n (\%)) & & & $2.63(1.11-6.25) / 2.10(0.79-5.58)$ & $0.023^{* *} / 0.136$ \\
\hline 6 month & $5(13 \%)$ & $3(8 \%)$ & & \\
\hline 12 month & $10(26 \%)$ & $3(8 \%)$ & & \\
\hline 24 month & $14(26 \%)$ & 7 (18\%) & & \\
\hline
\end{tabular}

of varices was achieved in 28 patients following an average of 2.8 (0.3) sessions. Four patients rebled prior to eradication and were entered into a regular long term TIPSS surveillance programme instead of regular VBL. Two patients died before eradication could take place. Another six patients did not complete the banding programme either because they were lost to follow up or because they refused further banding. Post-banding ulceration occurred in $12(30 \%)$ patients.

\section{Rebleeding}

In group 1, three episodes of variceal rebleeding occurred in three patients $(8 \%)$ during follow up, two with Child $\mathrm{C}$ and one with Child B disease (table 2 ). In two patients rebleeding proved to be rapidly fatal while in the third case the shunt was insufficient with a PPG of $18 \mathrm{~mm} \mathrm{Hg}$ and evidence of hepatic vein stenosis requiring shunt extension. This patient did not have a further rebleed and made a satisfactory recovery. In addition, there were four patients who rebled from non-variceal sources (two from banding ulceration, one from oesophagitis, and another from a Mallory Weiss tear).

In group 2 there were six episodes of variceal rebleeding in six patients (15\%) during follow up, two with Child A and four with Child C disease (table 2). Three of these patients had one further episode of variceal rebleeding during follow up. Varices were eradicated in only two patients. In all cases there was evidence of TIPSS insufficiency requiring restenting or balloon angioplasty. In all cases except one, variceal rebleeding was controlled. One patient who rebled from gastric varices initially responded to thrombin injection and balloon angioplasty of TIPSS. This patient had gastric varices at randomisation. However, he rebled again within 24 hours from gastric varices, despite a patent TIPSS. He unfortunately died from oesophageal rupture secondary to balloon tamponade. Three patients rebled from non-variceal sources (one from oesophagitis, one from a duodenal ulcer, and another from severe portal hypertensive gastropathy).

There was no significant difference in the cumulative risk of variceal rebleeding by Kaplan-Meier analysis $(p=0.440$; relative hazard $0.58 ; 95 \%$ confidence interval (CI) $0.15-2.33$ ) (fig 2, table 2). The two groups were similar even after controlling for PPG pre-TIPSS and sex (table 2).

\section{Mortality}

In group 1, there were 17 deaths (44\%) in total during follow up (table 2). Early mortality occurred in two patients from multiorgan failure resulting from the variceal bleed. The other causes of death were renal failure secondary to gentamicin therapy for a presumed shunt infection $(n=1)$, cerebrovascular accident $(\mathrm{n}=2)$, liver failure following non-variceal rebleeding $(\mathrm{n}=4)$, and for the remainder, multiorgan failure and sepsis.

In group 2, there were 15 deaths $(38 \%)$ in total during follow up (table 2). One patient died within six weeks of the index bleed from aspiration pneumonia. The causes of death were liver failure following variceal rebleeding $(\mathrm{n}=2)$, oesophageal rupture following insertion of a Sengstaken tube $(n=1)$, sepsis after a colectomy $(n=1)$, cerebrovascular accident $(\mathrm{n}=2)$, multiorgan failure $(\mathrm{n}=7)$, and pneumonia $(\mathrm{n}=1)$.

There was no statistically significant difference in the cumulative survival by the Kaplan-Meier method between the two groups $(\mathrm{p}=0.434$; relative hazard 1.31 ; $95 \%$ CI $0.66-$ 2.61 ) (fig 3, table 2). The two groups were similar even after controlling for PPG pre-TIPSS and sex (table 2).

\section{Encephalopathy}

In group 1,15 patients (39\%) in total developed encephalopathy during follow up (table 2 ). Four patients experienced deterioration of pre-existing encephalopathy. Two patients responded to conservative therapy with lactulose and protein restriction while the two other patients died with severe encephalopathy and liver failure. The remainder $(28 \%)$ had de novo encephalopathy. These patients were treated conservatively, with two patients requiring occlusion of the shunt with a filter and subsequent entry into a banding programme.

In group 2, eight patients $(20 \%)$ in total developed encephalopathy during follow up (table 2). Two patients were encephalopathic prior to TIPSS. Both responded to conservative therapy. The remainder (15\%) had de novo encephalopathy. Four responded to conservative therapy and two required occlusion of the shunt.

There was a significance difference (relative hazard 2.63; 95\% CI 1.11-6.25; p = 0.023) in favour of group 2 in the cumulative risk of being free of encephalopathy during the follow up period (fig 4, table 2). This difference did not maintain statistical significance after controlling for sex and PPG pre-TIPSS ( $p=0.136$; table 2 ). The cumulative risk of developing de novo encephalopathy was also significantly less in group $2(\mathrm{p}=0.041)$. Further analysis revealed that there was no significant difference $(p=0.386)$ in the incidence of hepatic encephalopathy in the first six months in the two groups, the period when the number of portograms was similar in groups 1 and 2 (25 v 27, respectively). However, the difference in hepatic encephalopathy in favour of group 2 remained statistically significant $(p=0.028)$ when the analysis was confined to the period from the end of the first six months of follow up, 


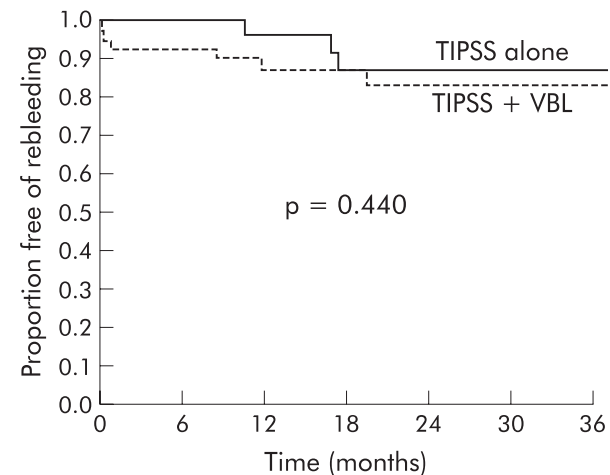

Time (months) $\quad 0 \quad 6 \quad 6 \quad 12 \quad 18 \quad 24 \quad 30 \quad 36$ TIPSS alone (n) $\begin{array}{llllllll}39 & 27 & 23 & 19 & 13 & 11 & 9\end{array}$ TIPSS + VBL (n) $4 \begin{array}{llllllll}40 & 34 & 28 & 26 & 20 & 13 & 10\end{array}$

Figure 2 Kaplan-Meier analysis of variceal rebleeding in the transjugular intrahepatic portosystemic stent shunt (TIPSS) alone group and in the TIPSS plus variceal band ligation group (TIPSS+VBL).

where there were far fewer portograms performed in group 2 $(10 \vee 21)$.

\section{Shunt function in the first year}

As TIPSS portography was performed only for up to one year following TIPSS insertion in group 2, valid comparisons of shunt function between the two groups can only be made for the 12 months following TIPSS insertion.

In group 1, a total of 46 TIPSS portograms were performed in the first year, with $54 \%$ of these performed in the first six months. A total of $16(41 \%)$ patients developed shunt insufficiency. In the first 12 months, 59\% of shunt interventions were performed within the first six months following TIPSS insertion.

In group 2, a total of 37 TIPSS portograms were performed in the first year, with $73 \%$ of these in the first six months. There were $17(43 \%)$ cases of shunt insufficiency in the first 12 months. There was no difference in the cumulative risk of shunt insufficiency in the two groups by the Kaplan-Meier Method (fig 5).

\section{Orthotopic liver transplantation (OLT)}

Four patients, all from group 1, underwent OLT during the follow up period, between 9.1 and 40.4 months after TIPSS creation. Most patients in both groups were unsuitable for

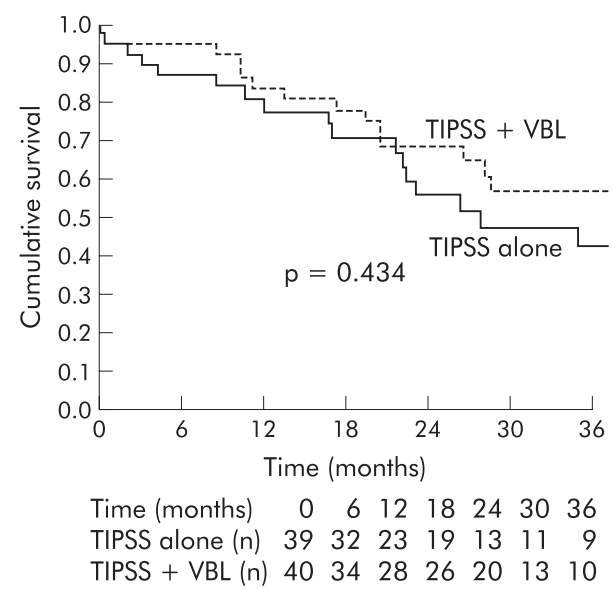

Figure 3 Kaplan-Meier analysis of cumulative survival in the transjugular intrahepatic portosystemic stent shunt (TIPSS) alone group and in the TIPSS plus variceal band ligation group (TIPSS+VBL).

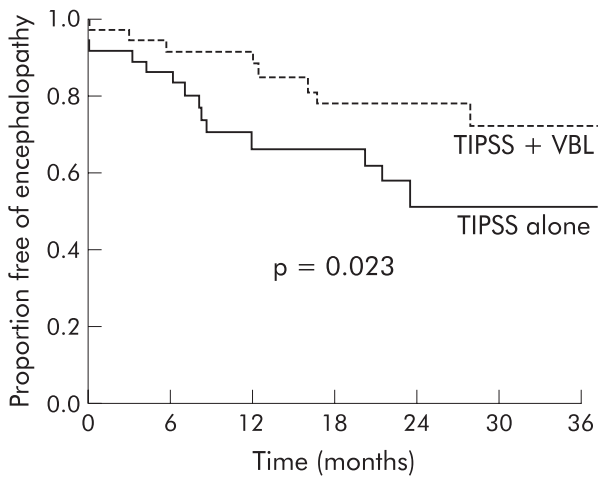

Time (months) $\quad 0 \quad 6 \quad 6 \quad 12 \quad 18 \quad 24 \quad 30 \quad 36$

TIPSS alone (n) $39 \begin{array}{lllllll}39 & 29 & 17 & 15 & 8 & 6 & 5\end{array}$ TIPSS + VBL (n) $4 \begin{array}{llllllll}40 & 33 & 27 & 22 & 17 & 11 & 8\end{array}$

Figure 4 Kaplan-Meier analysis of encephalopathy in the transjugular intrahepatic portosystemic stent shunt (TIPSS) alone group and in the TIPSS plus variceal band ligation group (TIPSS+VBL).

OLT on account of the high incidence of continued alcohol consumption (table 1 ).

\section{Duration of hospital stay}

Total requirements for inpatient care were similar in the two groups during follow up: 46.5 (54.5) versus 58.0 (65.2) days in groups 1 and 2 , respectively $(\mathrm{p}=0.396)$. There was also no difference in intensive care or high dependency care requirements (table 3 ).

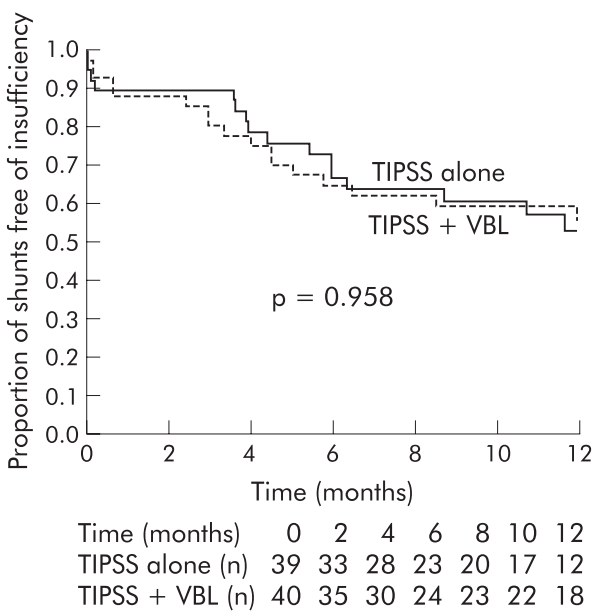

Figure 5 Kaplan-Meier analysis of 12 month shunt insufficiency in the transjugular intrahepatic portosystemic stent shunt (TIPSS) alone group and in the TIPSS plus variceal band ligation group (TIPPS+VBL).

Table 3 Days spent in hospital during follow up

\begin{tabular}{lcc}
\hline & \multicolumn{2}{l}{ Days in hospital per patient } \\
\cline { 2 - 3 } Ward & TIPSS $(\mathbf{n}=\mathbf{3 9})$ & TIPSS+VBL $(\mathbf{n}=40)$ \\
\hline General ward & $43.9(54.0)$ & $55.0(64.2)$ \\
HDU & $1.8(1.4)$ & $1.9(1.9)$ \\
ITU & $0.8(2.1)$ & $1.1(3.3)$ \\
Total & $46.5(54.5)$ & $58.0(65.2)$
\end{tabular}

Values are mean (SD).

TIPSS, transjugular intrahepatic portosystemic stent shunt; VBL, variceal band ligation; ITU, intensive care unit; HDU, high dependency unit. No significant difference was detected between the two groups. 
Table 4 Costs of treatments following randomisation in both groups

\begin{tabular}{|c|c|c|}
\hline \multirow[b]{2}{*}{ Procedure } & \multicolumn{2}{|c|}{ Cost per patient $(£)$} \\
\hline & TIPSS $(n=39)$ & TIPSS+VBL $(n=40)$ \\
\hline TIPSS surveillance & $877(930)$ & 805 (969) \\
\hline VBL & - & $1270(985)$ \\
\hline Ward treatment & 17004 (19154) & 20983 (23823) \\
\hline Total cost & 19560 (19146) & 24738 (24299) \\
\hline Cost per patient free of rebleeding & $20633 t$ & $24520 \ddagger$ \\
\hline Cost per surviving patient & $15922 \S$ & $20127 \cdot$ \\
\hline Cost per month survived ${ }^{*}$ & 4576 & 6024 \\
\hline \multicolumn{3}{|c|}{$\begin{array}{l}\text { Values are mean (SD). } \\
\text { *Total cost per patient divided by the follow up time in months. } \\
t n=36 ; \neq n=34 ; \xi n=22 ; \quad n=24 \text {. } \\
\text { There was no significant difference in costs between the two groups. }\end{array}$} \\
\hline
\end{tabular}

\section{Costs of treatment}

Table 4 details the costs incurred in both groups following randomisation. The difference in total cost per patient did not reach statistical significance (£19 560 (19 146) $v \quad £ 24738$ (24 299), $\mathrm{p}=0.297$, in groups 1 and 2, respectively).

\section{Severity of liver disease at the end of follow up}

The Child-Pugh score did not change significantly at the end of follow up (8.9 (2.6) $v 9.2(2.2), \mathrm{p}=0.609$, groups $\mathrm{l}$ and 2 , respectively).

\section{DISCUSSION}

TIPSS has now become accepted as a method of treating variceal bleeding refractory to endoscopic methods, and for the prevention of variceal rebleeding. We have shown for the first time that VBL can replace long term TIPSS surveillance for patients who have required a TIPSS for bleeding oesophageal varices.

The rebleeding rates in the two groups were not significantly different, even after adjustment for sex and portal pressure, and are consistent with previous trials. ${ }^{3}$ Although the absolute cumulative risk of variceal rebleeding was higher in group $2(15 \% \vee 8 \%)$, this did not reach statistical significance. The lack of statistical difference needs to be interpreted with caution in view of the wide confidence intervals (table 2), and the fact that the power calculations allow for large differences in the two groups. However, it must be emphasised that the absolute risk of variceal rebleeding in group 2 appears less than that seen with VBL alone, as demonstrated in a recent study performed in our unit. $^{?}$

Likewise, mortality was not different in the two groups, even after adjusting for differences in sex and portal pressure at baseline, and is in keeping with most of the previous studies comparing TIPSS and endoscopic modalities. $^{3-11}$ 23-26 The two groups were well matched for degree of liver disease, age, alcoholic aetiology, requirement for mechanical ventilation, time to randomisation from the index bleed, and encephalopathy pre-TIPSS; all variables which our unit and others have shown to predict mortality post-TIPSS. ${ }^{27-30}$

Encephalopathy, both overall and de novo, was significantly less in group 2 and is similar to that seen with VBL alone when used for secondary prophylaxis of variceal haemorrhage (fig 4). ${ }^{3}$ This difference is maintained when the first six months of follow up is excluded, following which time there are fewer interventions in group 2 to maintain shunt patency. However, in the first six months following TIPSS insertion, the period of maximum and equivalent shunt interventions in both groups, there was no difference in the incidence of hepatic encephalopathy. As shunt patency in group l was maintained by regular portographic surveillance and intervention throughout the study period, the fact that this group had greater episodes of encephalopathy would be expected. The rate of encephalopathy (39\%) seen in group $\mathrm{l}$ is similar to that published in the recent literature, ${ }^{3}$ with de novo encephalopathy being significantly less frequent. ${ }^{20}$ The majority of patients responded to conservative measures, with only four $(5 \%)$ patients in total requiring blockage of the TIPSS. The significance of the difference in encephalopathy was not maintained after controlling for PPG pre-TIPSS and sex (table 2). However, there did not appear to be any detrimental effects of TIPSS combined with VBL, and this regimen certainly has the potential to reduce the rate of hepatic encephalopathy.

The severity of liver disease, quantified by the Child-Pugh score, did not change significantly in both groups during follow up. This may be explained by the fact that most patients had alcoholic liver disease, with most patients continuing to consume alcohol. A recent study demonstrated improvement in Child-Pugh score following TIPSS ${ }^{31}$ but there were fewer patients with alcoholic cirrhosis and it is not clear how many people abstained.

We have shown that the rates of shunt insufficiency in the first year were similar in the two groups, with most episodes occurring in the first six months following TIPSS creation. This important observation suggests that portographic follow up is of most value for the first few months following TIPSS insertion and may not be required for one year. However, at the time of the study design, we were more conservative with respect to TIPSS surveillance. In all cases of variceal rebleeding, where portography was performed, there was evidence of shunt insufficiency.

There was a trend towards higher costs in the TIPSS+VBL group, the lack of statistical significance being due to a high standard deviation in costs (table 4) and the small sample size. With longer follow up, the costs differences may lessen as patients in the TIPSS+VBL group will only be followed up by endoscopy and VBL if required. One could even put forward a case for no surveillance in group 2, provided every attempt was made to eradicate varices early. This could significantly reduce costs and increase the use of TIPSS as follow up after TIPSS insertion can occur in any hospital with endoscopy and banding facilities.

In conclusion, for the first time, our findings suggest that VBL can replace long term TIPSS surveillance and still maintain low rates of variceal rebleeding with the potential to reduce the rates of post-TIPSS encephalopathy. Therefore, in patients who have bled from oesophageal varices, combining TIPSS and short term surveillance with VBL is a suitable alternative to TIPSS with long term surveillance in the prevention of variceal rebleeding. 


\section{ACKNOWLEDGEMENTS}

We would like to thank Dr NDC Finlayson, Dr AJ MacGilchrist, and Dr KJ Simpson for their support with the study. We also wish to acknowledge the administrative assistance of research nurses Sister Kim Macbeth and Sister Gwenyth Wilkie in arranging trial follow up.

\section{Authors' affiliations}

D Tripathi, H F Lui, A Helmyt, K Dabos, E Forresłł, A J Stanleył,

R Jalan§, P C Hayes, Liver Unit, The Royal Infirmary, Edinburgh, UK

D N Redhead, Department of Radiology, The Royal Infirmary, Edinburgh, UK

Present addresses:

*Singapore General Hospital, Outram Rd, Singapore †Department of Gastroenterology and Tropical Medicine, Assiut University Hospital, Assiut, 71111, Egypt

†Department of Gastroenterology, Glasgow Royal Infirmary, 84 Castle St, Glasgow G4 OSF, UK

§Institute of Hepatology, University College London, 69-75 Cheynes

Mews, London WC1E 6HX, UK

\section{REFERENCES}

1 Brett BT, Hayes PC, Jalan R. Primary prophylaxis of variceal bleeding in cirrhosis. Eur J Gastroenterol Hepatol 2001;13:349-58.

2 de Franchis R, Primignani M. Natural history of portal hypertension in patients with cirrhosis. Clin Liver Dis 2001;5:645-63.

3 Papatheodoridis GV, Goulis J, Leandro G, et al. Transjugular intrahepatic portosystemic shunt compared with endoscopic treatment for prevention of variceal rebleeding: A meta-analysis. Hepatology 1999;30:612-22.

4 Luca A, D'Amico G, La Galla R, et al. TIPS for prevention of recurrent bleeding in patients with cirrhosis: meta-analysis of randomized clinical trials. Radiology 1999;212:41 1-21.

5 Cabrera J, Maynar M, Granados R, et al. Transjugular intrahepatic portosystemic shunt versus sclerotherapy in the elective treatment of variceal hemorrhage. Gastroenterology 1996;1 10:832-9.

6 Garcia-Villarreal L, Martinez-Lagares F, Sierra A, et al. Transjugular intrahepatic portosystemic shunt versus endoscopic sclerotherapy for the prevention of variceal rebleeding after recent variceal hemorrhage. Hepatology 1999;29:27-32.

7 Jalan R, Forrest EH, Stanley AJ, et al. A randomized trial comparing transjugular intrahepatic portosystemic stent-shunt with variceal band ligation in the prevention of rebleeding from esophageal varices. Hepatology 1997;26:1115-22.

8 Merli M, Salerno F, Riggio $O$, et al. Transjugular intrahepatic portosystemic shunt versus endoscopic sclerotherapy for the prevention of variceal bleeding in cirrhosis: a randomized multicenter trial. Gruppo Italiano Studio TIPS (G.I.S.T.). Hepatology 1998;27:48-53.

9 Rossle M, Deibert P, Haag K, et al. Randomised trial of transjugularintrahepatic-portosystemic shunt versus endoscopy plus propranolol for prevention of variceal rebleeding. Lancet 1997;349:1043-9.

10 Sanyal AJ, Freedman AM, Luketic VA, et al. Transjugular intrahepatic portosystemic shunts compared with endoscopic sclerotherapy for the prevention of recurrent variceal hemorrhage. A randomized, controlled trial. Ann Intern Med 1997; 126:849-57.

11 Saver P, Theilmann L, Stremmel W, et al. Transjugular intrahepatic portosystemic stent shunt versus sclerotherapy plus propranolol for variceal rebleeding. Gastroenterology 1997;113:1623-31.
12 Haskal ZJ, Pentecost MJ, Soulen MC, et al. Transjugular intrahepatic portosystemic shunt stenosis and revision: early and midterm results. Am J Roentgenol 1994; 163:439-44.

13 Jalan R, Stanley AJ, Redhead DN, et al. Shunt insufficiency after transjugular intrahepatic portosystemic stent-shunt: the whens, whys, hows and what should we do about it? Clin Radiol 1997;52:329-31.

14 Jalan R, Hayes PC, Redhead DN. Shunt insufficiency after TIPSS. CardiovasC Intervent Radiol 1998;21:187-8.

15 Latimer J, Bawa SM, Rees CJ, et al. Patency and reintervention rates during routine TIPSS surveillance. Cardiovasc Intervent Radiol 1998;21:234-9.

16 Lind CD, Malisch TW, Chong WK, et al. Incidence of shunt occlusion or stenosis following transjugular intrahepatic portosystemic shunt placement. Gastroenterology 1994; 106:1277-83.

17 Stanley AJ, Redhead DN, Hayes PC. Review article: update on the role of transjugular intrahepatic portosystemic stent-shunt (TIPSS) in the management of complications of portal hypertension. Aliment Pharmacol Ther 1997; 11:261-72.

18 Ferguson JM, Jalan R, Redhead DN, et al. The role of duplex and colour Doppler ultrasound in the follow-up evaluation of transjugular intrahepatic portosystemic stent shunt (TIPSS). Br J Radiol 1995;68:587-9.

19 Peto R, Pike MC, Armitage P, et al. Design and analysis of randomized clinical trials requiring prolonged observation of each patient. II. Analysis and examples. Br J Cancer 1977:35:1-39.

20 Blackwelder WC. "Proving the null hypothesis" in clinical trials. Control Clin Trials 1982;3:345-53.

21 Jalan R, Redhead DN, Simpson KJ, et al. Transjugular intrahepatic portosystemic stent-shunt (TIPSS): long-term follow-up. Q J Med 1994;87:565-73.

22 Parsons-Smith BC, Sumerskill WHJ, Dawson AM. The electroencephalogram in liver disease. Lancet 1957;2:867-71.

23 Groupe d'Etude des Anastomoses Intra-Hepatiques (Toulouse BLNCPF). TIPS vs sclerotherapy+propranolol in the prevention of variceal rebleeding: preliminary results of a multicenter randomized trial. Hepatology 1995;22:299A.

24 Cello JP, Ring EJ, Olcott EW, et al. Endoscopic sclerotherapy compared with percutaneous transjugular intrahepatic portosystemic shunt after initial sclerotherapy in patients with acute variceal hemorrhage. A randomized, controlled trial. Ann Intern Med 1997; 126:858-65.

25 Pomier-Layrargues G, Dufresne MP, Bui B, et al. TIPS versus endoscopic variceal ligation in the prevention of variceal rebleeding in cirrhotic patients: a comparative randomized clinical trial (interim analysis). Hepatology 1997;26:137A.

26 Saver P, Benz C, Theilmann L, et al. Transjugular intrahepatic portosystemic stent shunt (TIPS) vs. endoscopic banding in the prevention of variceal rebleeding: final results of a randomized study. Gastroenterology 1998; 114:A1334.

27 Jalan R, Elton RA, Redhead DN, et al. Analysis of prognostic variables in the prediction of mortality, shunt failure, variceal rebleeding and encephalopathy following the transjugular intrahepatic portosystemic stent-shunt for variceal haemorrhage. J Hepatol 1995;23:123-8.

28 Smith JL, Graham DY. Variceal hemorrhage: a critical evaluation of survival analysis. Gastroenterology 1982;82:968-73.

29 Tyburski JG, Noorily MJ, Wilson RF. Prognostic factors with the use of the transjugular intrahepatic portosystemic shunt for bleeding varices. Arch Surg 1997; 132:626-30

30 Williams D, Waugh R, Gallagher N, et al. Mortality and rebleeding following transjugular intrahepatic portosystemic stent shunt for variceal haemorrhage. J Gastroenterol Hepatol 1998;13:163-9.

31 Escorsell A, Banares R, Garcia-Pagan JC, et al. TIPS versus drug therapy in preventing variceal rebleeding in advanced cirrhosis: A randomized controlled trial. Hepatology 2002;35:385-92. 